\title{
JUSTIÇA ORGANIZACIONAL, PRAZER E SOFRIMENTO NO TRABALHO: ANÁLISE DE UM MODELO MEDIACIONAL
}

\section{ORGANIZACIONAL JUSTICE, PLEASURE AND SUFFERING AT WORK: INTERPOSED ANALYZE MODEL}

\section{IZABELA A. DE C. MEIRELES DE O. SOUSA}

Mestre em Psicologia Organizacional e do Trabalho pela Universidade Católica de Goiás (UCG).

Professora convidada do Departamento de Psicologia da Universidade Católica de Goiás. Rua Alameda das Rosas, 109, Setor Oeste - Goiânia - GO - Brasil - CEP 741 10-060 E-mail: belameireles@hotmail.com

\section{HELEENIDES MENDONÇA}

Doutora em Psicologia Organizacional e do Trabalho pela Universidade de Brasília (UnB). Professora do Departamento de Psicologia da Universidade Católica de Goiás (UCG). Avenida Universitária, 1069, caixa postal 86, Setor Universitário Goiânia - GO - Brasil - CEP 74605-010 E-mail: helenides@ucg.br 


\section{RESUMO}

O presente estudo tem como objetivo analisar as relações entre as percepções de justiça distributiva e as vivências de prazer e sofrimento, mediadas pelas percepções das justiças processual e interacional. Propõe testar um modelo de análise mediacional entre a variável independente - percepção de justiça distributiva -, as variáveis dependentes - vivências de prazer e sofrimento no trabalho - e as variáveis mediadoras - percepção das justiças processual e interacional. Participaram do estudo 20 I trabalhadores de uma organização pública do segmento penitenciário. Os dados foram coletados por meio de um instrumento autoaplicável, contendo escalas de medida dos indicadores de prazer e sofrimento no trabalho e das percepções de justiça organizacional. Os resultados apontam que o modelo mediacional foi adequado para testar as relações entre as variáveis, sendo a justiça processual mediadora entre a justiça distributiva e a vivência de prazer; e as justiças interacional e processual, mediadoras da relação entre justiça distributiva e vivência de sofrimento.

\section{PALAVRAS-CHAVE}

Trabalho; Justiça organizacional; Prazer; Sofrimento; Modelo mediacional.

\section{ABSTRACT}

The following study's purpouse (intent) is to analyse the relations between the perceptions of distributive justice and the experience of pleasure (joy/delight) and suffering (pain/anguish/sorrow) interposed (interfered) by the perceptions of processual and interational justice. It suggests the testo $\mathrm{f}$ a modelo $\mathrm{f}$ interposed analysis (interfered analysis) between the independent (autonomous) variants - perception of distributive justice -, the dependent variants - experience of pleasure (joy/delight) and suffering (pain/anguish/sorrow) at work - and the interposed (interfered) variants - perceptions of processual and interational justice. $20 \mathrm{I}$ civil 
service employees of the penitentiary segment (section/division) took part in the research (study). The information was collected (gathered) using a self applicable instrument, containing scales of the index-fingers measured of pleasure and suffering at work and of the perceptions of organizational justice. The results show (prove) that the interposed (interfered) model was adjusted (fit/adapted) to test the relations between the variants: processual justice mediator of distributive justice and the experience of pleasure; and interational and processual justices mediators of the relation between distributive justice and the experience of suffering.

\section{KEYWORDS}

Work; Organizational justice; Pleasure; Suffering; Interposed analysis.

\section{INTRODUÇÃO}

As mudanças e transformações ocorridas no mundo do trabalho - econômicas, sociais e tecnológicas - exigem das organizações que pretendem continuar produtivas novos modelos de gestão.

Diante desse contexto e para que o indivíduo possa ter uma boa qualidade de vida no ambiente laboral, determinadas condições são necessárias: a compatibilidade da estrutura física em relação às atividades desenvolvidas, a adequação e consistência das relações interpessoais que permeiam o ambiente de trabalho e a satisfação dos indivíduos perante a dinâmica sistêmica que envolve as organizações de trabalho.

Nessa dinâmica, as percepções do trabalhador acerca dos processos decisórios, da distribuição de recursos e recompensas, e das relações interpessoais podem influenciar diretamente as vivências de prazer e de sofrimento psíquico, e consequentemente a qualidade de vida no trabalho. Portanto, este estudo abordará as percepções de justiça organizacional e suas consequentes vivências de prazer e sofrimento psíquico.

O debate acerca das vivências de prazer e sofrimento foi consolidado sob a abordagem da psicodinâmica, teoria desenvolvida por Dejours (I987). Para esse autor, essas vivências são consideradas como indicadores de saúde psíquica no ambiente de trabalho, onde, para preservá-la, os trabalhadores buscam o prazer e tentam evitar o sofrimento.

Os estudos sobre justiça, em contrapartida, ganharam força nas últimas quatro décadas. Vários autores (HOMANS, I96I; ADAMS, I965; THIBAUT; WALKER, I975; LEVENTHAL, I980; BIES; MOAG, I986; PAZ, I992; MEN- 
DONÇA, 2003; MENDONÇA; TAMAYO, 2004) contribuíram e contribuem para a compreensão das funções que tal conceito exerce nos sistemas da sociedade e do mundo do trabalho. Esses estudos vêm demonstrando que as percepções de justiça ou de injustiça podem afetar diretamente o desempenho laboral.

Na perspectiva de elucidar possíveis relações entre essas variáveis, este estudo pretende responder às seguintes questões empíricas:

- Até que ponto um trabalhador que percebe sua organização como injusta vivenciará sofrimento no trabalho ou, ao contrário, percebendo-a como justa, terá experiências de prazer?

- Um trabalhador percebendo seu salário como injusto poderia experienciar seu trabalho como fonte de sofrimento?

- Essa percepção poderá ser mediada por uma relação harmônica com o chefe?

- Da mesma forma, se perceber a inadequação dos procedimentos organizacionais, mas gozando de um bom relacionamento interpessoal, o trabalhador poderá sentir prazer no trabalho?

- Em contexto organizacional caracterizado por procedimentos equitativos, benefícios adequados e bom relacionamento interpessoal entre chefia e subordinado, o trabalhador vivencia mais prazer do que sofrimento?

Com base nessas questões, este estudo aborda os principais trabalhos encontrados na literatura estabelecendo um debate acerca do impacto da justiça sobre as vivências de prazer e sofrimento, e apresenta os resultados de uma investigação empírica que testa um modelo mediacional dessa relação.

\section{VIVÊNCIAS DE PRAZER E SOFRIMENTO NO TRABALHO}

As relações que o homem estabelece com o seu trabalho em termos daquilo que ele percebe como justo ou injusto e o impacto disso nas vivências de prazer e sofrimento psíquico serão o principal objeto de estudo deste artigo.

Essa temática é analisada com base na abordagem psicodinâmica que não enfatiza o diagnóstico das doenças ocupacionais, mas centra sua análise nas representações dos trabalhadores, bem como em suas experiências e vivências no cotidiano de trabalho. Nessa abordagem, o trabalho é concebido como um local de produção de significações psíquicas e de construção de relações sociais, sendo uma mediação entre o psíquico e o social. Essas significações são percebidas e vivenciadas por cada trabalhador. Assim, as vivências de prazer e sofrimen- 
to são manifestações dessa subjetividade, com sintomas relacionados ao contexto socioprofissional e à personalidade (DEJOURS, I987).

Para Mendes (I999), o sofrimento no trabalho é caracterizado por uma vivência frequente e permanente, muitas vezes inconsciente, de experiências dolorosas como angústia, medo e insegurança, provenientes do conflito entre as necessidades de gratificação do binômio corpo-mente e as restrições impostas nas situações de trabalho. Ainda sob o ponto de vista dessa autora, o prazer é caracterizado por uma vivência frequente e permanente, muitas vezes inconsciente, de experiências de extrema satisfação, provenientes da realização dos desejos, originados do binômio corpo-mente quando da gratificação pulsional encontrada no confronto com as diversas situações de trabalho.

Assim, as vivências de prazer e sofrimento encontram-se na mediação entre realidade psíquica e realidade sociocultural. O sofrimento é um mobilizador para a busca de prazer, um sinal de que algo não está funcionando bem, tendo o condão de possibilitar transformações e a busca de estruturação psíquica no trabalho, trazendo consequências positivas para a organização e para o próprio trabalhador.

O trabalho, portanto, é um encontro com o prazer, e o sofrimento instala-se quando a realidade não oferece as possibilidades de gratificação dos desejos, e é no tipo de organização do trabalho e funcionamento organizacional específico que se encontram as origens desse sofrer, experiência transitória a constituir-se em mobilizador para a busca de prazer (MENDES, I999).

Estudos de Mendes (I994) e Mendes e Abrahão (I996) demonstraram que o prazer é vivenciado quando o trabalho favorece a valorização e o reconhecimento, especialmente pela realização de uma tarefa significativa e importante para a organização e a sociedade. O uso da criatividade e a possibilidade de expressar uma marca pessoal também são fontes de prazer, além do orgulho e da admiração por aquilo que o trabalhador realiza, sentimentos somados ao reconhecimento da chefia e dos colegas.

A luta pela perpetuação das vivências de prazer no trabalho se justifica no fato de ser o trabalho um estruturante psíquico, levando, por isso, o trabalhador a um movimento constante de busca de prazer e evitação ou transformação do sofrimento para manter o seu equilíbrio psíquico.

Essas vivências, que são subjetivas a cada indivíduo, podem ser percebidas também pela forma como uma organização se desenvolve. É importante que essa organização tenha como princípios morais e éticos um senso de justiça focado nos procedimentos organizacionais, com a distribuição de recursos e recompensas e por meio da relações interpessoais.

Em consonância com a proposta teórica de Mendonça e Mendes (2005), este estudo considera que, diante da vivência de situações desfavoráveis - salário 
mais baixo do que o esperado, hostilidades no tratamento interpessoal dado pela chefia e a não participação em processo de promoção -, ocorrem descontentamento e indignação. Essas situações provocam sofrimento psíquico e ameaçam o bem-estar do trabalhador.

\section{PERCEPÇÕES DE JUSTIÇA ORGANIZ̃ACIONAL}

Para Assmar (1997), a justiça é essencial às pessoas dentro dos grupos sociais, uma vez que seus pensamentos, sentimentos e comportamentos são afetados pelos julgamentos que fazem sobre a justiça ou injustiça acerca de suas experiências. Os sentimentos das pessoas sobre justiça constituem base importante para suas reações aos outros, assim como para as vivências de prazer e sofrimento. Nesse sentido, a experiência de injustiça afeta não só o indivíduo como membro de um grupo social, mas também os demais membros desse grupo. Considerando o trabalho como um grupo social, a justiça, construída socialmente, terá influência determinante nas atitudes e nos comportamentos emitidos nesse contexto.

Mendonça e Tamayo (2004) afirmam que, no contexto organizacional, existem diferentes fatores que influenciam a percepção de justiça. Para esses autores, é importante que os gerentes entendam quando e em que condições os trabalhadores consideram como justas as distribuições de recursos e os procedimentos, sejam eles em relação às políticas formais ou em termos das relações interpessoais entre gerentes e subordinados.

Com o avanço teórico dos estudos sobre justiça, é possível visualizar que as pessoas não se interessam exclusivamente pelos resultados e pelas recompensas que recebem nas diversas situações sociais em que estão envolvidas. Para Thibaut e Walker (I975), os indivíduos avaliam de forma diferenciada o que é justo ou não em relação aos procedimentos de tomada de decisão e não unicamente a partir dos recursos disponibilizados.

Estudos de Cropanzano e Folger (I989) e de Greenberg (I987) revelaram que, quando os procedimentos são percebidos como justos, os trabalhadores ficam menos preocupados com os resultados injustos e tendem a considerar justo o que é injusto. Nesse sentido, esses autores atribuem maior força à justiça processual do que à justiça distributiva.

Ainda assim, a literatura sobre essa temática sugere que a forma como esses procedimentos são implementados deve ser mais bem compreendida (BIES; MOAG, I986). Destaca-se, com isso, a justiça interacional que, para Moorman 
(I99I), é a mais importante, uma vez que as relações interpessoais são mais determinantes nos comportamentos e nas atitudes das pessoas nas organizações do que os procedimentos e benefícios. Para Bies e Moag (I986, p. 44), a justiça interacional refere-se às concepções das pessoas sobre a "qualidade do tratamento interpessoal que recebem durante os procedimentos organizacionais".

De acordo com Mendonça et al. (2003), justiça organizacional é um construto que se manifesta de três maneiras distintas. Assim, para que se possa analisar a justiça, devem-se considerar a alocação de recursos (justiça distributiva), a organização formal dos procedimentos (justiça processual) e as relações interpessoais entre chefia e subordinados (justiça interacional).

Assim como em Bies (200I), este estudo baseia-se no pressuposto de que os resultados de estudos acerca da dimensionalidade da justiça organizacional não são conclusivos.

Isso posto, o artigo que ora se apresenta tem como objetivo testar um modelo teórico conceitual que apresenta as justiças processual e interacional como variáveis mediadoras na relação entre a justiça distributiva e as vivências de prazer e sofrimento. Ademais, a justiça organizacional é considerada como um construto multidimensional, uma vez que não leva em conta apenas o indivíduo, mas também a interação e o contexto no qual a justiça emerge.

\section{MODELO DE ANÁLISE}

Neste estudo, pretendeu-se testar um modelo mediacional para explicar as possíveis relações e influências entre as percepções de justiça organizacional, levando em consideração três tipos de justiça - distributiva, processual e interacional - e as vivências de prazer e sofrimento no trabalho.

De acordo com Baron e Kenny (I986), a variável mediadora (VMe) é uma terceira variável que deve predizer a variável dependente (VD), e a variável independente (VI) deve ser preditora da variável mediadora. Assim, na presença de ambas - VI e VMe -, uma relação significativa prévia entre a VI e a VD decresce em magnitude, demonstrando o efeito mediacional.

Esse modelo é caracterizado por uma relação que altera para mais ou para menos a influência da VI sobre a VD. O modelo mediacional explica as diferentes maneiras pelas quais a VI influencia a VD. Nesse sentido, encontra-se uma relação direta entre VI e VD, assim como uma relação mediada por uma terceira variável (MENDONÇA; COSTA NETO, 2005). A Figura I apresenta o modelo mediacional. 


\section{FigurA I}

\section{DIAGRAMA DO MODELO MEDIACIONAL}

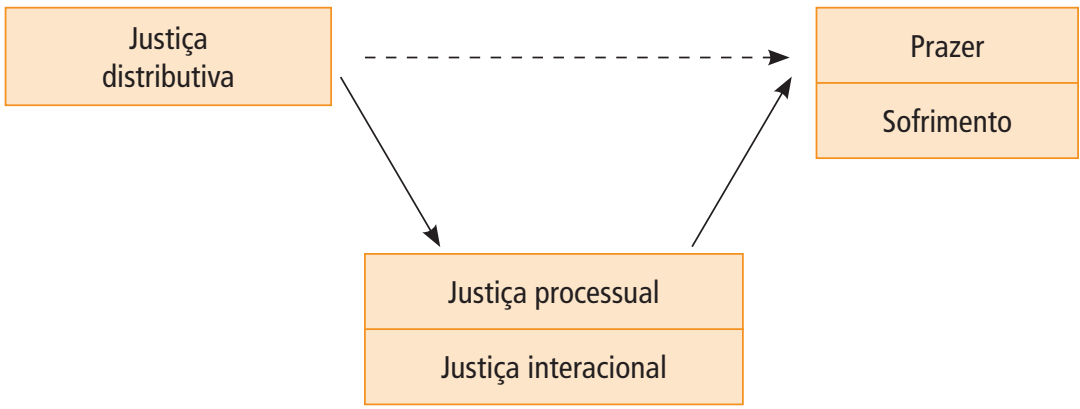

Fonte: Elaborada pelas autoras.

Esse modelo pretende analisar as relações entre as percepções de justiça distributiva (VI) e as vivências de prazer e de sofrimento (VD) mediadas pelas percepções das justiças processual e interacional (VMe).

\section{MÉTODO}

Participaram da pesquisa 20I trabalhadores de uma instituição do setor público, que desenvolvem suas atividades no segmento penitenciário. Os dados foram coletados de uma amostra estratificada para funções administrativas e agentes prisionais. Dos trabalhadores pesquisados, $55 \%$ exerciam o cargo de agente prisional e $45 \%$ atuavam em funções administrativas. Foram incluídos na amostra apenas os trabalhadores com mais de seis meses de serviço. Dentre os participantes, $79 \%$ eram do sexo masculino e $21 \%$ do sexo feminino. A idade média foi igual a 33 anos $(d p=9,8)$, e o tempo de serviço médio, de 5,8 anos $(d p=7,4)$. Quanto à escolaridade, $57 \%$ dos participantes da amostra haviam concluído o terceiro grau; $39 \%$, o segundo grau; e $4 \%$, o primeiro grau.

Para a realização desta pesquisa, utilizou-se um questionário com duas escalas: a Escala de Percepção de Justiça Organizacional (Epjo), validada por Mendonça et al. (2003), e a Escala de Indicadores de Prazer e Sofrimento no Trabalho (Eipst), desenvolvida por Mendes (I999). A Epjo é composta por 20 itens organizados no formato Likert, com escalas variando em cinco pontos (de I - discordo totalmente - a 5 - concordo totalmente). Os autores adotaram o modelo tridimensional com base no pressuposto de que o construto justiça é composto por três dimensões: distributiva, processual e interacional. A Eipst é composta por 36 itens organizados no formato Likert, com escalas variando em sete pontos, em 
que I corresponde a nunca e 7 a sempre. Essa escala representa uma estrutura fatorial dividida em dois fatores: vivência de prazer e vivência de sofrimento. Algumas questões referentes a cada variável estão apresentadas no Apêndice I.

Após autorização da direção superior da instituição, foi feita a coleta de dados coletivamente, no próprio local de trabalho. Os trabalhadores, para devolverem o questionário, recebiam um envelope lacrado, garantindo o sigilo das respostas.

\section{RESULTADOS E DISCUSSÃO}

O teste do modelo empírico proposto foi realizado por meio da análise de regressão linear hierárquica. Essa análise abrangeu a variável independente do modelo (a percepção de justiça distributiva), as variáveis mediadoras (as percepções das justiças processual e interacional) e as variáveis dependentes (as vivências de prazer e sofrimento).

A interpretação dos efeitos de mediação foi realizada conforme os passos explicitados por Baron e Kenny (1986):

- Passo I: a relação entre a variável preditora (VI) e a variável critério (VD) deve ser significativa.

- Passo 2: a variável preditora deve estar relacionada com a variável mediadora.

- Passo 3: o mediador deve relacionar-se com a variável critério após o efeito do preditor ter sido controlado.

- Passo 4: deve haver uma redução na força da associação entre as variáveis preditora e critério quando o mediador é considerado no modelo.

Assim, no primeiro passo, analisou-se a influência da VI - justiça distributiva - sobre a VD - prazer. Em seguida, fez-se a análise de regressão incluindo a VI - justiça distributiva - sobre as variáveis mediadoras - justiça interacional e processual (Passo 2). Finalmente, procedeu-se à análise incluindo todas as variáveis, como VI os três tipos de justiça e como VD a vivência de prazer (Passo 3).

No que se refere ao prazer, os resultados da regressão $[\mathrm{R}=0,34 ; \mathrm{F}(\mathrm{I} / \mathrm{I} 7 \mathrm{I})=$ 22,62; $\mathrm{p}<0,00 \mathrm{I}]$ revelaram (Tabela I) que a justiça distributiva é preditora do prazer numa relação direta $(\beta=0,34 ; t=4,75 ; p<0,00 \mathrm{I})$. Ao introduzir a variável mediadora, a relação entre justiça distributiva e prazer deixa de ser significativa $(\beta=0,08$; NS. A justiça processual passa a ser a maior preditora das vivências de prazer $[R=0,44 ; \mathrm{F}(3 / \mathrm{I} 7 \mathrm{I})=\mathrm{I} 3,46 ; \mathrm{p}<0,00 \mathrm{I}]$ e $(\beta=0,26 ; \mathrm{t}=2, \mathrm{I} 7 ; \mathrm{p}<0,05)$. Esses resultados indicam que os trabalhadores sentem prazer no trabalho quando percebem que os procedimentos organizacionais e a participação em tomadas de decisões são justos. 


\section{TABELA I}

RESULTADOS DA REGRESSÃO HIERÁRQUICA APLICADA À ANÁLISE DOS PREDITORES DA VIVÊNCIA DE PRAZER

\begin{tabular}{|c|c|c|c|c|c|c|}
\hline \multirow{3}{*}{ VARIÁVEIS INDEPENDENTES } & \multicolumn{6}{|c|}{ VIVÊNCIAS DE PRAZER } \\
\hline & \multicolumn{3}{|c|}{ PASSO 1} & \multicolumn{3}{|c|}{ PASSO 3} \\
\hline & BETA & $\mathrm{t}$ & $p<$ & BETA & $\mathrm{t}$ & $p<$ \\
\hline Justiça distributiva & 0,34 & 4,75 & 0,001 & 0,08 & 0,84 & NS \\
\hline Justiça processual & & & & 0,26 & 2,17 & 0,05 \\
\hline Justiça interacional & & & & 0,15 & 1,24 & NS \\
\hline $\begin{array}{l}\text { Coeficiente de regressão } \\
\text { múltipla }\end{array}$ & \multicolumn{3}{|c|}{$R=0,34$} & \multicolumn{3}{|c|}{$R=0,44$} \\
\hline Explicação da variabilidade & \multicolumn{3}{|c|}{$\mathrm{R}^{2}$ ajustado $=0,11$} & \multicolumn{3}{|c|}{$\mathrm{R}^{2}$ ajustado $=0,18$} \\
\hline Teste estatístico & \multicolumn{3}{|c|}{$F(1 / 171)=22,62 ; p<0,001$} & \multicolumn{3}{|c|}{$F(3 / 171)=13,46 ; p<0,001$} \\
\hline
\end{tabular}

Observação: A vivência de prazer varia de I (nunca) a 7 (sempre). As variáveis que compõem os tipos de justiça variam de I (discordo totalmente) a 5 (concordo totalmente).

Fonte: Elaborada pelas autoras.

Para confirmar se a variável preditora estava relacionada com a variável mediadora (Passo 2), foram realizadas duas regressões. No que se refere à justiça interacional, os resultados da regressão $[\mathrm{R}=0,8 \mathrm{I} ; \mathrm{F}(2 / \mathrm{I} 7 \mathrm{I})=\mathrm{I} 60,04 ; \mathrm{p}<$ $0,00 \mathrm{I}]$ revelaram (Tabela 2) que tanto a justiça distributiva $(\beta=0,25 ; \mathrm{t}=4, \mathrm{I} 4$; $\mathrm{p}<0,00 \mathrm{I})$ quanto a processual $(\beta=0,63$; $\mathrm{t}=\mathrm{I0}, 50$; $\mathrm{p}<0,00 \mathrm{I})$ são preditoras da justiça interacional numa relação direta. Os trabalhadores podem perceber o tratamento recebido pelas chefias como justo se considerarem que os benefícios, as recompensas e os procedimentos organizacionais também são justos.

Em relação à justiça processual, os resultados da regressão $[\mathrm{R}=0,8 \mathrm{I} ; \mathrm{F}(\mathrm{I} / \mathrm{I79})$ $=\mathrm{I} 32, \mathrm{I} 9 ; \mathrm{p}<\mathrm{O}, \mathrm{OO} \mathrm{I}]$ demonstraram que a justiça distributiva $(\beta=0,65 ; \mathrm{t}=\mathrm{II}, 50$;

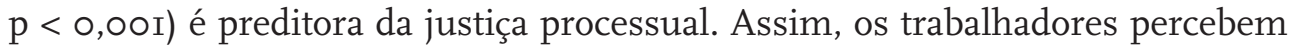
os procedimentos organizacionais como justos quando consideram que os benefícios e as recompensas também o são. 
TABELA 2

RESULTADOS DA REGRESSÃO HIERÁRQUICA APLICADA A ANÁLISE DOS MEDIADORES DA VIVÊNCIA DE PRAZER E SOFRIMENTO

\begin{tabular}{|c|c|c|c|c|c|c|}
\hline \multirow{3}{*}{ VARIÁVEIS INDEPENDENTES } & \multicolumn{6}{|c|}{ VARIÁVEIS MEDIADORAS } \\
\hline & \multicolumn{3}{|c|}{ JUSTIÇA INTERACIONAL } & \multicolumn{3}{|c|}{ JUSTIÇA PROCESSUAL } \\
\hline & BETA & $t$ & $p<$ & BETA & $\mathrm{t}$ & $p<$ \\
\hline Justiça processual & 0,63 & 10,50 & 0,001 & & & \\
\hline Justiça distributiva & 0,25 & 4,14 & 0,001 & 0,65 & 11,50 & 0,001 \\
\hline Coeficiente de regressão & \multicolumn{3}{|c|}{$R=0,81$} & \multicolumn{3}{|c|}{$R=0,65$} \\
\hline Variância explicada & \multicolumn{3}{|c|}{$\mathrm{R}^{2}$ ajustado $=0,65$} & \multicolumn{3}{|c|}{$\mathrm{R}^{2}$ ajustado $=0,42$} \\
\hline Teste estatístico & \multicolumn{3}{|c|}{$F(2 / 171)=160,04 ; p<0,001$} & \multicolumn{3}{|c|}{$F(1 / 179)=132,19 ; p<0,001$} \\
\hline
\end{tabular}

Observação: A vivência de prazer varia de I (nunca) a 7 (sempre). As variáveis que compõem os tipos de justiça variam de I (discordo totalmente) a 5 (concordo totalmente).

Fonte: Elaborada pelas autoras.

Os resultados deste estudo se coadunam com os achados de Barling e Phillips (I993), que estabelecem que tanto a justiça distributiva quanto a de procedimentos predizem atitudes em relação ao pagamento e à alocação de recompensas, mas apenas a justiça de procedimentos afeta a atitude dos trabalhadores em relação à organização.

Para os trabalhadores, o fato de perceberem a alocação de recursos, recompensas e benefícios como justos favorece o prazer de maneira direta, entretanto essa relação perde força ao ser introduzida a variável mediadora que, neste caso, é a justiça processual. Tomados em conjunto, ao ser introduzida no modelo a variável mediacional, constata-se maior poder explicativo acerca das vivências de prazer.

Os resultados aqui obtidos confirmam a teoria de Gomide (I999). Para o autor, dois aspectos devem ser observados no que se refere à justiça: o procedimento e a distribuição. Os trabalhadores podem perceber suas organizações de trabalho como justas se receberem não apenas um salário compatível com seus esforços, mas também benefícios e recompensas. Mais ainda, se tiverem a oportunidade de participar dos processos de tomada de decisão e expor suas ideias diante dos procedimentos organizacionais.

Quando há essa percepção de justiça, os trabalhadores podem vivenciar mais prazer no seu trabalho. Os resultados deste estudo confirmam essa rela- 
ção, o que nos remete à hipótese explicativa de que a organização pesquisada preocupa-se com esses fatores.

Outros estudos (MENDES, I994; MENDES; ABRAHÃO, I996) já demonstraram que o prazer é vivenciado quando o trabalho favorece a valorização e o reconhecimento, especialmente pela realização de uma tarefa significativa e importante para a organização e a sociedade. O uso da criatividade e a possibilidade de expressar sua marca pessoal também são fontes de prazer, além do orgulho e da admiração por aquilo que o trabalhador realiza, sentimentos somados ao reconhecimento da chefia e dos colegas.

$\mathrm{Na}$ organização pesquisada, constatou-se que os trabalhadores vivenciam mais prazer $(M=5,7)$ do que sofrimento $(M=3,6)$.

No que se refere às vivências de sofrimento, os resultados da regressão $[\mathrm{R}=$ $0,66 ; \mathrm{F}(\mathrm{I} / \mathrm{I} 7 \mathrm{I})=\mathrm{I} 28, \mathrm{I} 3 ; \mathrm{p}<0,00 \mathrm{I}]$ revelaram (Tabela 3) que a justiça distributiva é preditora do sofrimento numa relação direta $(\beta=-0,66 ; \mathrm{t}=-\mathrm{II}, 32 ; \mathrm{p}<0,00 \mathrm{I})$. Quando se introduzem as variáveis mediadoras, a influência da justiça distributiva diminui $(\beta=-0,33 ; \mathrm{t}=-4,57 ; \mathrm{p}<0,00 \mathrm{I})$. A justiça processual passa a predizer o sofrimento $(\beta=-0, I 7 ; t=-I, 96 ; p=0,05)$. Mas é a justiça interacional que, de fato, apresenta-se como a maior preditora do sofrimento $[\mathrm{R}=0,74 ; \mathrm{F}(3 / \mathrm{I} 7 \mathrm{I})=$ $68,25 ; \mathrm{p}<0,00 \mathrm{I}]$ e $(\beta=-0,33 ; \mathrm{t}=-3,74 ; \mathrm{p}<0,00 \mathrm{I})$.

\section{TABELA 3}

RESULTADOS DA REGRESSÃO HIERÁRQUICA APLICADA A ANÁLISE DOS PREDITORES DA VIVÊNCIA DE SOFRIMENTO

\begin{tabular}{|c|c|c|c|c|c|c|}
\hline \multirow{3}{*}{ VARIÁVEIS INDEPENDENTES } & \multicolumn{6}{|c|}{ VIVÊNCIAS DE SOFRIMENTO } \\
\hline & \multicolumn{3}{|c|}{ PASSO 1} & \multicolumn{3}{|c|}{ PASSO 3} \\
\hline & BETA & $\mathrm{t}$ & $p<$ & BETA & $\mathrm{t}$ & $p<$ \\
\hline Justiça distributiva & $-0,66$ & $-11,32$ & 0,001 & $-0,33$ & $-4,57$ & 0,001 \\
\hline Justiça interacional & & & & $-0,33$ & $-3,74$ & 0,001 \\
\hline Justiça processual & & & & $-0,17$ & $-1,96$ & $=0,05$ \\
\hline Coeficiente de regressão & \multicolumn{3}{|c|}{$R=0,66$} & \multicolumn{3}{|c|}{$R=0,74$} \\
\hline Variância explicada & \multicolumn{3}{|c|}{$\mathrm{R}^{2}$ ajustado $=0,43$} & \multicolumn{3}{|c|}{$\mathrm{R}^{2}$ ajustado $=0,54$} \\
\hline Teste estatístico & \multicolumn{3}{|c|}{$F(1 / 171)=128,13 ; p<0,001$} & \multicolumn{3}{|c|}{$F(3 / 171)=68,25 ; p<0,001$} \\
\hline
\end{tabular}

Observação: A vivência de sofrimento varia de i (nunca) a 7 (sempre). As variáveis que compõem os tipos de justiça variam de I (discordo totalmente) a 5 (concordo totalmente).

Fonte: Elaborada pelas autoras. 
Os dois tipos de justiça - processual e interacional - mediaram o impacto da justiça distributiva sobre as vivências de sofrimento, o que significa que, ao perceberem seus salários como injustos, os trabalhadores podem vivenciar sofrimento. No entanto, essa relação, de fato, fica mais forte se perceberem como injustos os procedimentos e a participação em tomadas de decisões, e mais forte ainda se considerarem que o tratamento recebido de seus chefes é injusto.

Diante de tais resultados, infere-se que a injustiça interacional na relação é causadora de maior sofrimento. Uma hipótese explicativa para essa relação é o fato de que o sofrimento tem um caráter afetivo muito forte, haja vista serem as percepções de justiça interacional os melhores preditores do sofrimento psíquico no trabalho.

Para Moorman (I99I), a justiça interacional é mais importante no contexto organizacional, uma vez que as relações interpessoais são mais determinantes nos comportamentos e nas atitudes das pessoas dentro das organizações do que os procedimentos e benefícios conquistados.

De acordo com os resultados apresentados, conclui-se que o modelo mediacional foi confirmado porque encontraram-se explicações de maior magnitude na equação que engloba todas as variáveis: as justiças distributiva e processual como preditoras das vivências de prazer, e as justiças distributiva e interacional como preditoras das vivências de sofrimento.

Diante desses resultados, constata-se que a alocação e distribuição de recursos podem influenciar diretamente as vivências de prazer ou sofrimento no trabalho, entretanto a influência mediacional das percepções das justiças processual e interacional é determinante na explicação dessas vivências.

Em relação às vivências de prazer, infere-se que o sentimento de pertencer a um grupo de forma integral, ou seja, não estar ali trabalhando aleatoriamente, contribui para uma vivência de prazer. Os trabalhadores devem entender o funcionamento da organização, os seus procedimentos organizacionais e as suas dinâmicas.

No que se refere às vivências de sofrimento, os resultados do estudo demonstram que o principal mediador é a percepção de que o trabalhador recebe um tratamento justo da chefia - justiça interacional. Assim, mesmo quando os trabalhadores percebem que os procedimentos são justos, se não forem reconhecidos, aceitos e bem tratados pelos seus chefes, podem vivenciar sofrimento no trabalho.

Esses resultados coadunam os pressupostos da abordagem da psicodinâmica ao demonstrarem que a valorização e o reconhecimento levam ao prazer. O trabalho é considerado pelo indivíduo como realização e identidade, porque geralmente, quando produz, ele se sente estruturado como pessoa em decorrência de estar valorizado e ser reconhecido pelo que faz. Trata-se do desejo de permanecer 
produzindo e de encontrar no trabalho a oportunidade para construir-se como sujeito psicológico e social, confirmando sua importância para a sociedade. Esse sentimento fortalece o ânimo do indivíduo em relação ao trabalho, que se transforma em fonte de prazer.

\subsection{TESTE DO MODELO MEDIACIONAL}

Baron e Kenny (I986), em seus estudos sobre a distinção entre as variáveis mediadoras e moderadoras, propõem o teste de Sobel $-z-$ para testar o efeito da variável independente sobre a variável dependente via variável mediadora.

O modelo proposto para este estudo foi confirmado pelo teste de Sobel $-z$ (Figura 2). Para o primeiro conjunto de regressões entre a justiça distributiva (VI) e o prazer (VD), foram testadas como mediadoras as justiça processual e interacional. A média obtida para a justiça processual confirma a mediação entre VI e VD $(z=2, I 3 ; p<0,05)$. A justiça interacional não se configura como mediadora entre a VI e a VD ( $z=\mathrm{I}, \mathrm{I} 5$; NS).

Já para o segundo conjunto de regressão entre a justiça distributiva (VI) e o sofrimento (VD), também foram testadas como mediadoras as justiças processual e interacional. A média obtida para a justiça processual confirma a mediação entre VI e VD: $z=-I, 92 ; \mathrm{P}=0,05$, porém com menos intensidade. A justiça interacional se configura como a maior mediadora entre VI e VD: $z=-2,73 ; \mathrm{p}<0,0 \mathrm{O}$.

\section{FIGURA 2}

\section{REPRESENTAÇÃO GRÁFICA DO MODELO MEDIACIONAL}

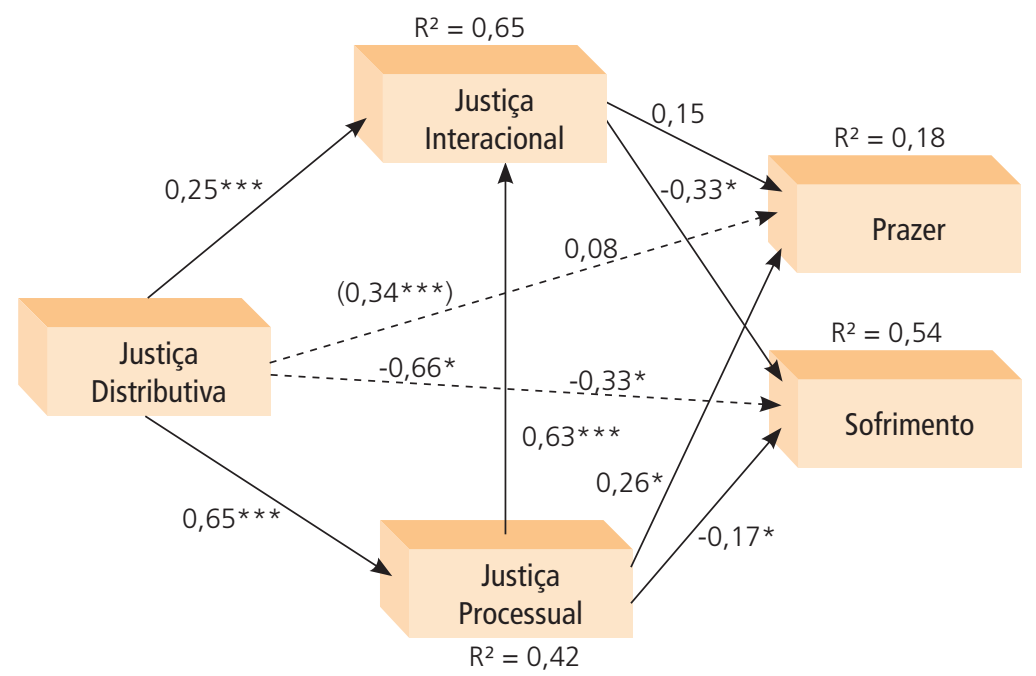

Fonte: Elaborada pelas autoras. 
Assim, conclui-se que o modelo mediacional foi confirmado, uma vez que foram encontradas explicações de maior magnitude na equação que engloba todas as variáveis: as justiças distributiva e processual como preditoras da vivência de prazer, e as justiças distributiva e interacional como preditoras da vivência de sofrimento.

Diante desses resultados, constata-se que os trabalhadores priorizam suas recompensas e seus benefícios, mas esses fatos não os fazem vivenciar prazer ou sofrimento no trabalho. O prazer se intensifica quando os trabalhadores percebem que estão participando dos processos de tomada de decisão na organização.

Infere-se que o sentimento de pertencer a um grupo de forma integral, ou seja, não estar ali trabalhando aleatoriamente, contribui para uma vivência de prazer. Os trabalhadores precisam entender todo o funcionamento da organização, os procedimentos organizacionais e as dinâmicas.

Mesmo quando os trabalhadores percebem que os procedimentos são justos, se não forem reconhecidos, aceitos e bem tratados pelos seus chefes, podem vivenciar sofrimento no trabalho.

\section{CONSIDERAÇÕES FINAIS}

Os resultados desta pesquisa podem contribuir de maneira significativa para o desenvolvimento de organizações que buscam preservar o bem-estar de seus trabalhadores.

Tomando como referência o modelo mediacional, nota-se que, na análise da relação entre percepção de justiça organizacional e vivências de prazer, a prioridade dada à participação nos procedimentos organizacionais está relacionada positivamente ao prazer. Ademais, a justiça processual medeia a relação entre a justiça distributiva e o prazer, e a justiça interacional é a mediadora na relação entre a justiça distributiva e o sofrimento.

Com base nesses resultados, a organização pesquisada pode traçar estratégias para a conscientização de todo o quadro de trabalhadores acerca dos procedimentos organizacionais, visando à qualificação das relações entre chefias e subordinados. De fato, os resultados evidenciam que mais importante do que a alocação e distribuição de recursos e recompensas como preditoras das vivências de prazer ou de sofrimento, é a participação nos processos de tomada de decisão.

Outro ponto a ser ressaltado como grande contribuição deste estudo relaciona-se aos indicadores de prazer e sofrimento psíquico. A revisão de literatura demonstra a ausência de estudos que apresentem as percepções de justiça como indicadores do prazer e do sofrimento psíquico. O modelo mediacional testado 
neste estudo apresenta essa relação de maneira significativa, demonstrando que os trabalhadores poderão vivenciar prazer ou sofrimento no trabalho a partir de suas percepções acerca da justiça organizacional.

Apesar dos resultados encorajadores obtidos neste estudo, a carência de pesquisas envolvendo os trabalhadores de agências prisionais impediu equiparações, consultas e análises comparativas de teorias e métodos.

Considera-se, portanto, este estudo como o passo preliminar na perspectiva de conhecer e aperfeiçoar as condições de trabalho para que a qualidade de vida desses trabalhadores seja estimulada e mantida dentro de um contexto que, pelas causas e motivações existentes, não favorece a valorização dos ofícios e a dignificação daqueles que laboram.

Diante dos resultados obtidos, pode-se dizer que este estudo atende aos objetivos propostos e responde à problemática anunciada. Entretanto, como ponto de partida de uma área de investigação carente de estudos empíricos, assinala-se a necessidade de serem desenvolvidas outras investigações.

\section{APÊNDICE}

\section{EXEMPLOS DE QUESTÕES DAS ESCALAS REFERENTES A CADA VARIÁVEL EMPÍRICA}

\begin{tabular}{|c|c|}
\hline VARIÁVEIS EMPÍRICAS & EXEMPLOS DE QUESTÕES DAS ESCALAS \\
\hline Justiça distributiva & $\begin{array}{l}1 \text { - Sou recompensado, de maneira justa, por minha } \\
\text { responsabilidade no trabalho. } \\
10 \text { - Sou recompensado, de maneira justa, pelo estresse a que sou } \\
\text { submetido durante o meu trabalho. }\end{array}$ \\
\hline Justiça processual & $\begin{array}{l}3 \text { - A minha empresa dá oportunidades para os empregados } \\
\text { recorrerem das decisões tomadas. } \\
19 \text { - No meu trabalho as pessoas podem solicitar esclarecimentos ou } \\
\text { informações adicionais sobre as decisões tomadas pelos chefes. }\end{array}$ \\
\hline Justiça interacional & $\begin{array}{l}2 \text { - Ao se relacionar com os empregados, o meu chefe consegue } \\
\text { superar os favorecimentos pessoais. } \\
16 \text { - O meu chefe me trata com sinceridade e franqueza. }\end{array}$ \\
\hline Vivência de prazer & $\begin{array}{l}1 \text { - Realizo-me profissionalmente. } \\
15 \text { - Tenho liberdade para organizar o meu trabalho. }\end{array}$ \\
\hline $\begin{array}{l}\text { Vivência de } \\
\text { sofrimento }\end{array}$ & $\begin{array}{l}11 \text { - Minhas tarefas são banais. } \\
28 \text { - Meu trabalho é desgastante. }\end{array}$ \\
\hline
\end{tabular}




\section{REFERÊNCIAS}

ADAMS, J. S. Inequity in social exchange. In: BERKOWITZ, L. (Ed.). Advances in experimental social psychology. New York: Academic Press, I965. v. 2.

ASSMAR, E. M. L. A experiência de injustiça na vida diária: uma análise preliminar em três grupos sociais. Psicologia: Reflexão e Crítica, v. Io, n. 2, p. 335-350, 1997.

BARLING, J.; PHILLIPS, M. Interactional, formal and distributive justice in the workplace: an exploratory study. The Journal of Psychology, v. 127, n. 6, p. 649-656, 1993.

BARON, R. M.; KENNY, D. A. The moderator-mediator variable distinction in social psychological research: conceptual, strategic and statistical considerations. Journal of Personality and Social Psychology, v. 5I, n. 6, p. II73-II82, I986.

BIES, R. J. Interactional (in)justice: the sacred and the profane. In: GREENBERG, J.; CROPANZANO, R. (Ed.). Advances in organizational justice. Califórnia: Stanford University Press, $200 \mathrm{I}$.

BIES, R. J.; MOAG, J. S. Interactional justice: communication criteria of fairness. In: LEWICKI, R. J.; SHEPPARD, B. H; BAZERMAN, M. H. (Ed.). Research on negotiation in organizations. Greenwich: Jairpress, I986.

CROPANZANO R.; FOLGER, R. Referent cognitions and task decisions autonomy: beyond equity theory. Journal af Applied Psychology, v. 74, n. 2, p. 293-299, 1989.

DEJOURS, C. A loucura do trabalho: estudo de psicopatologia do trabalho. São Paulo: Cortez, I987.

GOMIDE, S.J. Antecedentes e conseqüentes das percepções de justiça no trabalho. I999. Tese (Doutorado em Psicologia)-Universidade de Brasília, Brasília, I999.

GREENBERG, J. Reactions to procedural injustice in payment distributions: do the mean justify the ends? Journal of Applied Psychology, v. 72, n. I, p. 55-61, I987.

HOMANS, G. C. Social behavior: its elementary forms. New York: Harcourt, Brace \& World, I96I.

LEVENTHAL, G. S. What should be done with equity theory? In: GERGEN, K. J.; GREENBERG, J.; WEISS, R. H. (Ed.). Social exchange: advances in theory and research. New York: Plenum, I980.

MENDES, A. M. Prazer-sofrimento no trabalho qualificado: um estudo exploratório com engenheiros de uma empresa pública de telecomunicações. I994. Dissertação (Mestrado em Psicologia)-Universidade de Brasília, Brasília, I994.

Valores e vivência de prazer e sofrimento no trabalho. I999. Tese (Doutorado em Psicologia)-Universidade de Brasília, Brasília, I999.

MENDES, A. M.; ABRAHÃO, J. I. A influência da organização do trabalho nas vivências de prazersofrimento do trabalhador: uma abordagem psicodinâmica. Revista Psicologia: Teoria e Pesquisa, v. 26, n. 2, p. 179-184, 1996.

MENDONÇA, H. Retaliação organizacional: o impacto dos valores e da justiça. 2003. Tese (Doutorado em Psicologia)-Universidade de Brasília, Brasília, 2003.

MENDONÇA, H.; COSTA NETO, S. B. Valores e estratégias psicológicas de enfrentamento do estresse no trabalho. São Paulo: Casa do Psicólogo, 2005.

MENDONÇA, H. et al. Validação fatorial de uma escala de percepção de justiça organizacional. Estudos: Saúde e Vida, v. 30, n. I, p. III-I3O, 2003. 
MENDONÇA, H.; MENDES, A. M. Experiência de injustiça, sofrimento e retaliação no contexto de uma organização pública do Estado de Goiás. Psicologia em Estudo, Maringá, v. Io, n. 3, p. 489498, 2005 .

MENDONÇA, H.; TAMAYO, A. Percepção de justiça e atitudes retaliatórias nas organizações: análise empírica de um modelo atitudinal. Revista de Administração Contemporânea (RAC), v. 8, n. 2, p. II7-I35, 2004.

MOORMAN, R. H. Relationship between organizational justice and organizational citizenship behaviors: do fairness perceptions influence employee citizenship? Journal of Applied Psychology, v. 76, n. 6, p. 845-855, I991.

PAZ, M. G. T. Justiça distributiva na avaliação de desempenho dos trabalhadores de uma empresa estatal. I992. Tese (Doutorado em Psicologia)-Universidade de São Paulo, São Paulo, I992.

THIBAUT, J. W.; WALKER, L. Procedural justice: a psychological analyses. New York: Erlbaum, Hillsdale, I975. 